\title{
Metformin improves blood glucose by increasing incretins independent of changes in gluconeogenesis in youth with type 2 diabetes
}

\author{
Celeste K. L. Cravalho ${ }^{1}$ - Abby G. Meyers ${ }^{2} \cdot$ Lilian S. Mabundo $^{1} \cdot$ Amber Courville $^{3}$ - Shanna Yang ${ }^{3} \cdot$ Hongyi Cai $^{1}$. \\ Yuhai Dai ${ }^{1}$. Mary Walter ${ }^{1}$. Peter J. Walter ${ }^{1}$. Susan Sharma ${ }^{1}$. Shaji Chacko ${ }^{4}$. Fran Cogen ${ }^{5}$. Sheela N. Magge ${ }^{6}$. \\ Morey W. Haymond ${ }^{4} \cdot$ Stephanie T. Chung ${ }^{1}$ (D)
}

Received: 7 April 2020 / Accepted: 9 June 2020 / Published online: 29 July 2020

(C) This is a U.S. government work and not under copyright protection in the U.S.; foreign copyright protection may apply 2020

\begin{abstract}
Aims/hypothesis Metformin is the only approved oral agent for youth with type 2 diabetes but its mechanism of action remains controversial. Recent data in adults suggest a primary role for the enteroinsular pathway, but there are no data in youth, in whom metformin efficacy is only $\sim 50 \%$. Our objectives were to compare incretin concentrations and rates of glucose production and gluconeogenesis in youth with type 2 diabetes before and after short-term metformin therapy compared with peers with normal glucose tolerance (NGT).

Methods This is a case-control observational study in youth with type 2 diabetes who were not on metformin $(n=18)$ compared with youth with NGT $(n=10)$ who were evaluated with a 2 day protocol. A $75 \mathrm{~g}$ OGTT was administered to measure intact glucagon-like 1 peptide (iGLP-1), gastric inhibitory polypeptide (GIP) and peptide YY (PYY). Insulinogenic index (IGI) and whole-body insulin sensitivity were calculated using glucose and insulin levels from the OGTT. Basal rates of gluconeogenesis $\left({ }^{2} \mathrm{H}_{2} \mathrm{O}\right)$, glucose production $\left(\left[6,6-{ }^{2} \mathrm{H}_{2}\right]\right.$ glucose $)$ and whole-body lipolysis $\left(\left[{ }^{2} \mathrm{H}_{5}\right]\right.$ glycerol $)$ were measured after an overnight fast on study day 2 . Youth with type 2 diabetes $(n=9)$ were subsequently evaluated with an identical 2 day protocol after 3 months on the metformin study.

Results Compared with individuals with NGT, those with type 2 diabetes had higher fasting $(7.8 \pm 2.5 \mathrm{vs} 5.1 \pm 0.3 \mathrm{mmol} / \mathrm{l}$, mean $\pm \mathrm{SD} p=0.002)$ and $2 \mathrm{~h}$ glucose concentrations $(13.8 \pm 4.5 \mathrm{vs} 5.9 \pm 0.9 \mathrm{mmol} / \mathrm{l}, p=0.001)$, higher rates of absolute gluconeogenesis $\left(10.0 \pm 1.7 \mathrm{vs} 7.2 \pm 1.1 \mu \mathrm{mol}[\mathrm{kg} \text { fat-free mass }(\mathrm{FFM})]^{-1} \mathrm{~min}^{-1}, p<0.001\right)$ and whole-body lipolysis $(5.2 \pm 0.9 \mathrm{vs} 4.0 \pm$ $\left.1.4 \mu \mathrm{mol} \mathrm{kg} \mathrm{FFM}^{-1} \min ^{-1}, p<0.01\right)$, but lower fasting iGLP-1 concentrations $(0.5 \pm 0.5 \mathrm{vs} 1.3 \pm 0.7 \mathrm{pmol} / 1, p<0.01)$. Metformin decreased $2 \mathrm{~h}$ glucose (pre metformin $11.4 \pm 2.8 \mathrm{vs}$ post metformin $9.9 \pm 1.9 \mathrm{mmol} / \mathrm{l}, p=0.04$ ) and was associated with $\sim 20-50 \%$ increase in IGI (median [25th-75th percentile] pre 1.39 [0.89-1.47] vs post $1.43[0.88-2.70], p=0.04)$, fasting iGLP-1 (pre $0.3 \pm$ 0.2 vs post $1.0 \pm 0.7 \mathrm{pmol} / 1, p=0.02$ ), $2 \mathrm{~h}$ iGLP (pre $0.4 \pm 0.2$ vs post $1.2 \pm 0.9 \mathrm{pmol} / 1, p=0.06$ ), fasting PYY (pre $6.3 \pm 2.2 \mathrm{vs}$ post $10.5 \pm 4.3 \mathrm{pmol} / \mathrm{l}, p<0.01$ ) and $2 \mathrm{~h} \mathrm{PYY}$ (pre $6.6 \pm 2.9$ vs post $9.0 \pm 4.0 \mathrm{pmol} / 1, p<0.01$ ). There was no change in BMI, insulin sensitivity or GIP concentrations pre vs post metformin. There were no differences pre vs post metformin in rates of glucose production $\left(15.0 \pm 3.9 \mathrm{vs} 14.9 \pm 2.2 \mu \mathrm{mol} \mathrm{kg}{ }_{\mathrm{FFM}}{ }^{-1} \mathrm{~min}^{-1}, p=0.84\right)$, absolute gluconeogenesis $(9.9 \pm 1.8 \mathrm{vs} 9.7 \pm$ $\left.1.7 \mu \mathrm{mol} \mathrm{kg} \mathrm{FFM}^{-1} \min ^{-1}, p=0.76\right)$ or whole-body lipolysis $\left(5.0 \pm 0.7 \mathrm{vs} 5.3 \pm 1.3 \mu \mathrm{mol} \mathrm{kg}_{\mathrm{FFM}}{ }^{-1} \mathrm{~min}^{-1}, p=0.20\right)$. Post
\end{abstract}

Electronic supplementary material The online version of this article (https://doi.org/10.1007/s00125-020-05236-y) contains peer-reviewed but unedited supplementary material, which is available to authorised users.

Stephanie T. Chung

chungst@niddk.nih.gov

1 National Institute of Diabetes, Digestive and Kidney Diseases/ National Institutes of Health, 10 Center Dr. Bld 10-CRC, RM 5-3671, Bethesda, MD 20892, USA

2 National Institute of Child Health and Development, National Institutes of Health, Bethesda, MD, USA

3 National Institutes of Health, Clinical Center, Bethesda, MD, USA
4 Department of Pediatrics, Children's Nutrition Research Center and Division of Pediatric Endocrinology and Metabolism, U.S. Department of Agriculture/Agricultural Research Service, Baylor College of Medicine, Houston, TX, USA

5 Children's National Health Systems, Department of Pediatric Diabetes and Endocrinology, Washington, DC, USA

6 Division of Pediatric Endocrinology and Diabetes, Johns Hopkins University School of Medicine, Baltimore, MD, USA 


\section{Research in context}

\section{What is already known about this subject?}

- Metformin is the initial treatment of choice for youth and adults with type 2 diabetes but is suboptimal in $>50 \%$ of youth within 2 years of diagnosis

- Metformin's primary mechanism(s) of action are controversial and may be related to decreasing gluconeogenesis and/or increasing incretins via gut-mediated mechanisms

What is the key question?

- How much does the increase in incretins and decrease in gluconeogenesis contribute to metformin's glucoselowering effect in youth?

What are the new findings?

- Metformin lowered postprandial glucose and increased incretins (peptide YY and glucagon-like peptide-1) in the absence of changes in glucose production and gluconeogenesis

- These findings support an enteroinsular mechanistic pathway for metformin

How might this impact on clinical practice in the foreseeable future?

- Since increased gluconeogenesis is an important component of early-onset type 2 diabetes, our findings support the need to explore adjunctive therapies that can be used with metformin to reduce gluconeogenesis and augment the incretin response in youth with type 2 diabetes

metformin iGLP-1 and PYY concentrations in youth with type 2 diabetes were comparable to levels in youth with NGT. Conclusions/interpretation Overall, the improved postprandial blood glucose levels and increase in incretins observed in the absence of changes in insulin sensitivity and gluconeogenesis, support an enteroinsular mechanistic pathway in youth with type 2 diabetes treated with short-term metformin.

Keywords Gluconeogenesis · Gut hormones · Paediatric · Type 2 diabetes

$\begin{array}{ll}\text { Abbreviations } \\ \text { CNRC } & \text { Children's Nutrition Research Center } \\ \text { FFM } & \text { Fat-free mass } \\ \text { GIP } & \text { Gastric inhibitory polypeptide } \\ \text { GLP-1 } & \text { Glucagon-like peptide-1 } \\ \text { GPR } & \text { Glucose production rate } \\ \text { HISI } & \text { Hepatic insulin sensitivity index } \\ \text { IGI } & \text { Insulinogenic index } \\ \text { iGLP-1 } & \text { Intact GLP-1 } \\ \text { MIGHTY } & \text { Metformin Influences Gut Hormones in Youth } \\ \text { NGT } & \text { Normal glucose tolerance } \\ \text { NIH } & \text { National Institutes of Health } \\ \text { PYY } & \text { Peptide YY } \\ R_{\mathrm{a}} & \text { Rate of appearance } \\ \text { WBISI } & \text { Whole-body insulin sensitivity index }\end{array}$

\section{Introduction}

Metformin is the initial treatment of choice for youth and adults with type 2 diabetes but metformin monotherapy is suboptimal in up to $60 \%$ of youth with type 2 diabetes within
2 years of diagnosis [1]. The low metformin efficacy in children is unexpected for two main reasons: (1) metformin has an excellent safety and efficacy track record in adults [2, 3]; and (2) during the 8 week run-in phase of the landmark randomised controlled Treatment Options for type 2 Diabetes in Adolescents and Youth (TODAY) study more than $85 \%$ of youth, regardless of race, were able to maintain glycaemic control on metformin monotherapy [4]. Multiple socioenvironmental factors, including poor medication compliance, psychosocial stressors or access to care, could contribute to reduced long-term efficacy in youth but these factors do not explain the reduced efficacy observed in youth participating in randomised controlled trials [5]. Alternative mechanisms, such as disease-related differences in metformin's action in youth may provide additional insight. High failure rates of metformin in youth may be secondary to more severe hepatic insulin resistance early in the disease course as the biology of youth-onset type 2 diabetes is characterised by marked fasting hyperglycaemia and increased rates of gluconeogenesis in youth newly diagnosed with type 2 diabetes [6]. Rates of gluconeogenesis in youth are comparable with those seen in individuals with lipodystrophy 
and severe insulin resistance [7]. Classically, metformin is thought to lower blood glucose by decreasing hepatic glucose production (primarily gluconeogenesis) [8]. Therefore, the high treatment failure rates in youth are unexpected because metformin should directly target the high rates of gluconeogenesis in youth.

Over the last decade, an increasing number of articles have challenged a primary hepatocentric mechanism of action and suggested that metformin has more complex physiological targets [9]. In vivo tracer studies of hepatic glucose production are scarce, have only been undertaken in adults, and show mixed results (including either reduced or unchanged rates of gluconeogenesis) [8, 10-13]. Metformin-induced changes in the enteroinsular axis and the microbiome are emerging as important mechanistic targets [9]. Studies in adults suggest that short-term metformin therapy may directly or indirectly increase incretin hormone concentrations (glucagon-like peptide-1 [GLP-1] and peptide YY [PYY]) [14-17]. To date, there is a paucity of data concurrently examining the effect of metformin on gut hormone concentrations and changes in gluconeogenesis and glucose production in either children or adults. Moreover, the biological differences in the natural history of youth- vs adult-onset type 2 diabetes warrant paediatric and disease-specific critical evaluation of the pathways affected by metformin. In this study, we hypothesised that metformin would increase incretin concentrations but have little or no effect on lowering gluconeogenesis in youthonset type 2 diabetes. Our objectives were to compare incretin concentrations and rates of glucose production and gluconeogenesis in youth with type 2 diabetes before and after shortterm metformin therapy with those in a control group of peers with obesity and normal glucose tolerance (NGT).

\section{Methods}

The Metformin Influences Gut Hormones in Youth (MIGHTY) Study is an ancillary study of two protocols that were designed to evaluate the pathophysiology of type 2 diabetes in youth. The protocols were approved by the Baylor College of Medicine and the National Institute of Diabetes, and Digestive, and Kidney Diseases (NIDDK) Institutional Review Boards, respectively. Youth (aged 1017 years, $\mathrm{BMI} \geq 95$ th percentile for age and sex) were recruited from and evaluated consecutively at two study sites: The Children's Nutrition Research Center (CNRC) in Houston, TX, USA (2011-2013), and the Metabolic Clinical Research Unit at the National Institutes of Health (NIH), Clinical Center, Bethesda, MD, USA (2017-2018) (ClinicalTrials. gov registration no. NCT02960659). Data on baseline evaluation of gluconeogenesis in youth at Baylor College of Medicine has been previously reported [6].
Study design and participants Youth with type 2 diabetes and youth in the control NGT group were recruited to participate in the MIGHTY Study. Twenty-three youth with type 2 diabetes were recruited, 19 were evaluated at baseline (visit 2), and nine completed the metformin treatment study and were evaluated with a protocol identical to the baseline visit 2 after 3 months of metformin treatment (electronic supplementary material [ESM] Fig. 1). In the 19 with type 2 diabetes, nine were newly diagnosed and treatment naive and ten were on metformin treatment. Exclusion criteria were as follows: $>3$ years from diabetes diagnosis; treatment with insulin or a GLP-1 analogue within the previous 3 months; $\mathrm{HbA}_{1 \mathrm{c}}$ $>75 \mathrm{mmol} / \mathrm{mol}$ (9\%); ketonaemia; or positive autoantibodies to GAD, insulin and insulinoma-associated protein-2 (IA-2A). Youth in the control NGT group $(n=10)$ had a normal $75 \mathrm{~g}$ OGTT performed at the screening visit [18]. All adolescents were Tanner stage IV or V and were not taking hormonal contraceptives or lipid-lowering medications.

Study protocol The study timeline and protocol are outlined in ESM Fig. 2. Prior to visit 2, all glucose-lowering therapy was discontinued for 5-7 days. This washout period is equivalent to $\sim 8$ to 10 terminal half-lives for metformin elimination from both the erythrocyte and plasma compartments and accounts for multiple dosing [19]. During this period, all participants were advised to follow a glucose-lowering $\operatorname{diet}(7531.2 \mathrm{~kJ} /$ day [1800 kcal/day]) at home. For the type 2 diabetes group, fingerstick blood glucose concentrations were recorded twice daily. There were no episodes of acute hyperglycaemia (fasting glucose $\geq 13.9 \mathrm{mmol} / \mathrm{l}$ ), ketosis or symptoms of metabolic decompensation (abdominal pain or vomiting).

All participants (NGT and type 2 diabetes), were admitted to the clinic research centres for a 2 day study protocol (ESM Fig. 2b) [20]. On study day 1 , after an overnight $10 \mathrm{~h}$ fast, a multisample $75 \mathrm{~g} 2 \mathrm{~h}$ OGTT was administered to measure plasma glucose, insulin, glucagon and intact GLP-1 (iGLP-1) concentrations at $0,30,60,90$ and $120 \mathrm{~min}$. PYY and gastric inhibitory polypeptide (GIP) were measured at 0 and $120 \mathrm{~min}$. Standardised breakfast, lunch, snack and dinner meals were provided and participants' estimated energy needs were calculated using the Mifflin St Joer equation plus an activity factor of 1.2 [20]. Participants had ad libitum access to water and were fasted from 21:00 h on study day 1. Stable isotope kinetic studies using $\left[6,6-{ }^{2} \mathrm{H}_{2}\right]$ glucose and $\left[{ }^{2} \mathrm{H}_{5}\right]$ glycerol to measure glucose and glycerol turnover, respectively, and ${ }^{2} \mathrm{H}_{2} \mathrm{O}$ to measure fractional gluconeogenesis, were performed on study day 2 between $04: 00 \mathrm{~h}$ and 09:00 h. Fasting samples to measure glucagon, lactate, ketones and glycerol concentration were measured at 09:00 h. Prior to the tracer dilution studies at visit 2 , all participants had body composition (fat-free mass [FFM] and fat mass) measured by dual-energy x-ray absorptiometry (DEXA, QDR 11.2; Hologic, USA). FFM was used to calculate rates for 
isotope administration. Measurements of $\dot{V} \mathrm{O}_{2}$ and $\mathrm{CO}_{2}$ production were performed via indirect calorimetry during fasting near steady state when participants were reclined, still and awake between 07:00 $\mathrm{h}$ and 07:30 $\mathrm{h}$, using the DELTATRAC II (Sensormedics, USA) at the CNRC or the ParvoMedics TrueOne 2400 Metabolic Measurement System at NIH.

Metformin treatment study After visit 2, standard-release metformin was titrated as follows: $500 \mathrm{mg}$ daily for 1 week, $500 \mathrm{mg}$ twice daily for 1 week and then $1000 \mathrm{mg}$ twice daily for the remainder of the 3 month study. Two participants experienced diarrhoea and abdominal cramping and the dose of metformin was decreased to $1500 \mathrm{mg}$ daily. All participants remained on metformin 1500-2000 mg daily for 8 weeks prior to final testing at visit 5 . Daily blood glucose logs were reviewed weekly. Fasting metformin concentrations were measured after the washout period at baseline (day 1, visit 2) and after the 3 month study (day 1, visit 5) $\sim 12 \mathrm{~h}$ after the last study dose (ESM Table 1).

Tracers Deuterium oxide (99\% $\left.\left[{ }^{2} \mathrm{H}\right]\right),\left[6,6-{ }^{2} \mathrm{H}_{2}\right]$ glucose $(99 \%$ $\left.\left[{ }^{2} \mathrm{H}\right]\right),\left[1,2,3-{ }^{13} \mathrm{C}_{3}\right]$ glycerol $\left(99 \%{ }^{13} \mathrm{C}\right)$ and $\left[{ }^{2} \mathrm{H}_{5}\right]$ glycerol $(99 \%$ $\left.\left[{ }^{2} \mathrm{H}\right]\right)$ were purchased from Cambridge Isotope Laboratories (Andover, USA). In participants studied at the CNRC, the isotopes were tested for sterility and pyrogenicity by the investigational pharmacy at Texas Children's Hospital and the infusates were filtered through a Millex GP syringe filter $\left(0.22 \mu \mathrm{m}\right.$; Millipore Corporation, USA) and stored at $4{ }^{\circ} \mathrm{C}$ for up to $48 \mathrm{~h}$ prior to administration. For participants studied at the NIH, the isotopes were prepared and tested for sterility and pyrogenicity by the Pharmaceutical Development Service at the NIH Clinical Center and Pine Pharmaceuticals LLC (USA) and stored for up to 6 months prior to use.

Administration of tracers Participants received $3.0 \mathrm{~g} / \mathrm{kg}_{\mathrm{FFM}}$ of deuterium oxide $\left({ }^{2} \mathrm{H}_{2} \mathrm{O}\right)$ given in three or four divided doses between 21:00 $\mathrm{h}$ and 03:00 $\mathrm{h}$ to enrich the body water pool to approximately $0.3 \%{ }^{2} \mathrm{H}_{2} \mathrm{O}$ to measure fractional gluconeogenesis (ESM Fig. 2b). On study day 2, between 04:00 h and 09:00 $\mathrm{h}$, a simultaneous, primed ( $60 \times$ the $1 \mathrm{~min}$ infusion rate), $5 \mathrm{~h}$ constant-rate infusion was initiated with $\left[6,6-{ }^{2} \mathrm{H}_{2}\right]$ glucose $\left(0.09 \mathrm{mg} \mathrm{kg} \mathrm{FFM}^{-1} \mathrm{~min}^{-1}\right)$ and $\left[{ }^{2} \mathrm{H}_{5}\right]$ glycerol $(0.015 \mathrm{mg}$ $\mathrm{kg}_{\mathrm{FFM}}{ }^{-1} \mathrm{~min}^{-1}$ ) to measure glucose and glycerol turnover, respectively. Two of the nine youth in the NGT group were studied in an identical fashion as described above, except for $\left[1,2,3-{ }^{13} \mathrm{C}_{3}\right]$ glycerol (mean infusion rate $0.033 \mathrm{mg}$ $\mathrm{kg}_{\mathrm{FFM}}{ }^{-1} \mathrm{~min}^{-1}$ ) being substituted for $\left[{ }^{2} \mathrm{H}_{5}\right]$ glycerol due to tracer availability. Glycerol enrichment did not differ in these two individuals. Blood samples were obtained at baseline and during the fasting steady-state period (at $-30,-20,-10$ and $0 \mathrm{~min}$ during the last $30 \mathrm{~min}$ of the continuous tracer infusion) to assess plasma glucose and insulin concentrations, and isotopic enrichments of glucose and glycerol. Due to difficulties with the glycerol tracer supply at the NIH Clinical Center, the rate of glycerol production was not measured in one youth with type 2 diabetes at visit 2 and in two with type 2 diabetes at visit 5 .

Analyses Glucose concentrations were measured in plasma using an enzymatic hexokinase assay on the Cobas 6000 instrument (Roche Diagnostics, USA). Insulin was measured in plasma via electrochemiluminescence on the Cobas 6000 instrument (Roche Diagnostics). $\mathrm{HbA}_{1 \mathrm{c}}$ was determined using the HPLC D10 instrument (Bio-Rad, USA). Plasma samples for incretins and glucagon were collected in EDTA tubes with protease inhibitor, immediately centrifuged and plasma stored at $-80^{\circ} \mathrm{C}$ until analysis. Total GIP, iGLP-1 and total PYY concentrations were measured with Mesoscale ELISA Kits (USA) and were measured at 0 and $120 \mathrm{~min}$. The detection ranges were (in $\mathrm{pg} / \mathrm{ml}$ ) 73.4-2500 for GIP, $0.9-1000$ for iGLP-1 (7-36) and 68-24,000 for total PYY. Glucagon was measured with a Mercodia kit (USA) (detection range 1.5$120 \mathrm{pmol} / \mathrm{l}$ ). L-Lactate was measured by a colorimetric fluorescence assay (Cayman Chemical Company, USA). Total ketones and $\beta$-hydroxybutyrate were measured using an NMR Profiler and Vantera Clinical Analyzer platforms (LabCorp, formerly LipoScience, USA). The enrichments of $\left[6,6-{ }^{2} \mathrm{H}_{2}\right]$ glucose, $\left[{ }^{2} \mathrm{H}_{5}\right]$ glycerol, $\left[1,2,3{ }^{-13} \mathrm{C}_{3}\right]$ glycerol and $\left[{ }^{2} \mathrm{H}_{1}\right]$ glucose were determined as previously described $[7$, 21, 22]. Plasma glycerol concentration was measured by LC-MS (NIDDK) [23], and by reverse isotope dilution using $\left[2-{ }^{13} \mathrm{C}\right]$ glycerol (Baylor, USA) [22]. Detection of metformin and quantification of metformin concentrations were performed with ultraperformance LC-tandem MS (detection range $1-1000 \mathrm{ng} / \mathrm{ml}$; see ESM Methods for details). Results for incretin and glucose during the OGTT were not available in one youth with type 2 diabetes because of intolerance to the glucose drink. In the NGT group, $\mathrm{HbA}_{1 \mathrm{c}}$ was not measured in six youth because of insufficient sample volume.

Calculations Plasma glucose rate of appearance $\left(R_{\mathrm{a}}\right)$ and rate of glycerol production were calculated under near steady-state conditions ( -30 to $0 \mathrm{~min}$ ) using the average enrichment of $\left[6,6-{ }^{2} \mathrm{H}_{2}\right]$ glucose and $\left[{ }^{2} \mathrm{H}_{5}\right]$ glycerol or $\left[1,2,3-{ }^{13} \mathrm{C}_{3}\right]$ glycerol, with conventional isotope dilution calculations as previously described [22]. Under fasting and steady-state conditions, the glucose $R_{\mathrm{a}}$ is equivalent to glucose production. Fractional gluconeogenesis was determined using ${ }^{2} \mathrm{H}_{2} \mathrm{O}$ and the average enrichment of ${ }^{2} \mathrm{H}$ enrichments of carbon 1,3,4,5,6 of glucose as previously described [21]. The rate of gluconeogenesis was calculated as the product of glucose appearance and fractional gluconeogenesis (glucose $R_{\mathrm{a}} \times \%$ gluconeogenesis) and the rate of glycogenolysis was calculated as the glucose production rate (GPR) minus the rate of gluconeogenesis. Hepatic insulin sensitivity index (HISI) was calculated in the fasting state: $\operatorname{HISI}_{\mathrm{GPR}}=1000 /\left[\mathrm{GPR}\left(\mathrm{mg} \mathrm{kg}_{\mathrm{FFM}}{ }^{-1} \mathrm{~min}^{-1}\right) \times\right.$ plasma insulin concentration $(\mu \mathrm{U} / \mathrm{ml})$ ] [24]. During the OGTT, 
Table 1 Participants' characteristics

\begin{tabular}{|c|c|c|c|c|c|c|}
\hline \multirow[t]{2}{*}{ Variable } & \multirow[t]{2}{*}{$\operatorname{NGT}(n=10)$} & \multirow{2}{*}{$\begin{array}{l}\text { Type } 2 \text { diabetes } \\
(n=19)\end{array}$} & \multirow{2}{*}{$\begin{array}{l}p \text { value NGT } \\
\text { vs } \\
\text { type } 2 \text { diabetes }\end{array}$} & \multicolumn{3}{|c|}{ Type 2 diabetes $(n=9)$} \\
\hline & & & & Pre metformin & Post metformin & $\begin{array}{l}p \text { value pre vs } \\
\text { post }\end{array}$ \\
\hline \multicolumn{7}{|l|}{ Clinical characteristics } \\
\hline Female sex, $n(\%)$ & $8(80)$ & $15(79)$ & 0.67 & $9(100)$ & $9(100)$ & - \\
\hline Age, years & $14.8 \pm 2.0$ & $14.8 \pm 2.1$ & 0.97 & $14.6 \pm 2.6$ & $14.8 \pm 2.5$ & 0.04 \\
\hline Race/ethnicity, $n(\%)$ & & & 0.15 & & & - \\
\hline African American & $6(60)$ & $15(79)$ & & $5(56)$ & $5(56)$ & \\
\hline Hispanic & $2(20)$ & $4(21)$ & & $4(44)$ & $4(44)$ & \\
\hline White & $1(10)$ & 0 & & 0 & 0 & \\
\hline Mixed race & $1(10)$ & 0 & & 0 & 0 & \\
\hline BMI, $\mathrm{kg} / \mathrm{m}^{2}$ & $37 \pm 5$ & $40 \pm 7$ & 0.13 & $42 \pm 9$ & $41 \pm 8$ & 0.15 \\
\hline $\begin{array}{l}\text { BMI, } \% \text { of } 95 \text { th } \\
\text { percentile }\end{array}$ & $132 \pm 25$ & $147 \pm 21$ & 0.09 & $154 \pm 27$ & $148 \pm 26$ & 0.06 \\
\hline Fat mass, kg & $40.5 \pm 8.8$ & $50.7 \pm 13.9$ & 0.05 & - & - & \\
\hline Systolic BP, mmHg & $113 \pm 8$ & $124 \pm 12$ & 0.02 & $121 \pm 10$ & $120 \pm 9$ & 0.29 \\
\hline Diastolic BP, mmHg & $68 \pm 5$ & $72 \pm 9$ & 0.18 & $69 \pm 10$ & $70 \pm 9$ & 0.60 \\
\hline \multicolumn{7}{|l|}{ Metabolic characteristics } \\
\hline $\mathrm{HbA}_{1 \mathrm{c}}, \mathrm{mmol} / \mathrm{mol}$ & $35 \pm 3$ & $53 \pm 12$ & 0.005 & $46 \pm 7$ & $42 \pm 4$ & 0.07 \\
\hline $\mathrm{HbA}_{1 \mathrm{c}}, \%$ & $5.3 \pm 0.3$ & $7.0 \pm 1.1$ & 0.005 & $6.4 \pm 0.6$ & $6.0 \pm 0.3$ & 0.07 \\
\hline Fasting glucose, mmol/1 & $5.1 \pm 0.3$ & $7.8 \pm 2.5$ & 0.002 & $7.0 \pm 1.9$ & $6.1 \pm 1.0$ & 0.16 \\
\hline $2 \mathrm{~h}$ glucose, $\mathrm{mmol} / \mathrm{l}$ & $5.9 \pm 0.9$ & $13.8 \pm 4.5$ & 0.001 & $11.4 \pm 2.8$ & $9.9 \pm 1.9$ & 0.04 \\
\hline Fasting insulin, pmol/1 & $122.5(91.7-171.0)$ & $303.8(145.2-367.1)$ & 0.03 & $46.3(42.4-66.1)$ & $37.5(25.7-55.2)$ & 0.41 \\
\hline $2 \mathrm{~h}$ insulin, $\mathrm{pmol} / \mathrm{l}$ & $\begin{array}{l}391.6 \\
\quad(333.5-993.5)\end{array}$ & $839.0(548.7-1243.2)$ & 0.17 & $\begin{array}{l}157.4 \\
\quad(78.4-309.4)\end{array}$ & $\begin{array}{l}122.9 \\
\quad(63.4-202.4)\end{array}$ & 0.61 \\
\hline IGI & $3.11(1.85-4.37)$ & $0.93(0.43-1.44)$ & 0.001 & $1.39(0.89-1.47)$ & $1.43(0.88-2.70)$ & 0.04 \\
\hline WBISI & $2.2(1.95-3.61)$ & $0.97(0.69-1.46)$ & 0.002 & $0.94(0.64-1.04)$ & $1.38(0.71-2.11)$ & 0.87 \\
\hline \multicolumn{7}{|l|}{ Basal energy expenditure } \\
\hline REE (kJ/day) & $7442 \pm 1313$ & $8473 \pm 1264$ & 0.05 & $8644 \pm 1438$ & $7737 \pm 3010$ & 0.28 \\
\hline $\operatorname{REE}\left(\mathrm{kJ} \mathrm{kg}_{\mathrm{FFM}}{ }^{-1}\right.$ day $\left.^{-1}\right)$ & $136.4 \pm 13.7$ & $148.5 \pm 22.6$ & 0.14 & $154.5 \pm 23.5$ & $134.1 \pm 48.1$ & 0.28 \\
\hline RQ & $0.85 \pm 0.05$ & $0.80 \pm 0.04$ & 0.009 & $0.80 \pm 0.04$ & $0.80 \pm 0.05$ & 0.91 \\
\hline
\end{tabular}

Data are mean $\pm \mathrm{SD}, n(\%)$ or median (25th-75th percentile)

REE, resting energy expenditure; $R Q$, respiratory quotient

surrogate markers of insulin sensitivity and insulin secretion were calculated using the whole-body insulin sensitivity index (WBISI) [24] and the insulinogenic index (IGI) [25], respectively.

Statistical methods This study was designed to evaluate the change in glucose production with short-term metformin treatment in youth. Post hoc sample size calculations were performed to guide recruitment efforts. A sample size of eight youth would have $\geq 80 \%$ power to detect a $10 \%$ difference in GPR and rate of fractional gluconeogenesis, $\alpha=0.05$. Data are presented as mean $\pm \mathrm{SD}$ or median (25th-75th percentile) unless otherwise stated. The AUC during the OGTT $\left(\mathrm{iAUC}_{120}\right)$ was calculated using a cubic spline to determine the integral (Stata, v15.1; Stata, USA). Non-parametric data

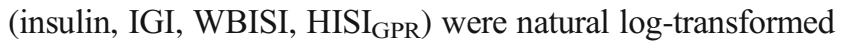

prior to analysis. Missing data were not imputed. Student's $t$ test and Fischer exact test were used to compare type 2 diabetes vs NGT, and paired $t$ tests were used to compare pre vs post metformin. Correlations were assessed with Pearson correlation coefficients $(r)$. Sensitivity analyses were performed to determine the effect of prior metformin use and $\mathrm{HbA}_{1 \mathrm{c}}$ on incretin and glucose outcomes. Statistical analyses were performed with Stata, v15.1 and $p$ values $<0.05$ were considered statistically significant.

\section{Results}

Participant demographic and clinical characteristics Demographic and metabolic characteristics at baseline (NGT and type 2 diabetes) and pre and post metformin are depicted 
in Table 1. Youth were $14.8 \pm 2$ years, $80 \%$ were female sex, $70 \%$ were African American, and had an average BMI of 38.8 $\pm 6.5 \mathrm{~kg} / \mathrm{m}^{2}$. There were no differences in these demographic characteristics by group (Table 1). Youth with type 2 diabetes had higher fasting $(7.8 \pm 2.5$ vs $5.1 \pm 0.3 \mathrm{mmol} / \mathrm{l}$, mean $\pm \mathrm{SD}$ $p=0.002)$ and $2 \mathrm{~h}$ plasma glucose $(13.8 \pm 4.5$ vs $5.9 \pm$ $0.9 \mathrm{mmol} / \mathrm{l}, p=0.001$ ) with lower IGI and WBISI (Table 1 ). At visit 5, post metformin, IGI was $\sim 20-50 \%$ higher (median [25th-75th percentile] pre 1.39 [0.89-1.47] vs post 1.43 [0.882.7], $p=0.04$ ), $2 \mathrm{~h}$ glucose was lower (pre metformin $11.4 \pm 2.8$ vs post metformin $9.9 \pm 1.9 \mathrm{mmol} / \mathrm{l}, p=0.04), \mathrm{HbA}_{1 \mathrm{c}}$ was lower (although the difference did not reach statistical significance), and there was no change in BMI, fasting glucose or WBISI, when compared with pre metformin (Table 1).

Incretin concentrations At visit 2, youth with type 2 diabetes, compared with NGT, had $50-60 \%$ lower fasting $(0.5 \pm 0.5$ vs $1.3 \pm 0.7 \mathrm{pmol} / \mathrm{l}, p<0.01), 2 \mathrm{~h}$ and $\mathrm{AUC}_{120}$ for iGLP-1 concentrations (Fig. 1a), but there were no differences in fasting and $2 \mathrm{~h}$ PYY or GIP concentrations (Fig. 2). At visit 5 post metformin, fasting (pre $0.3 \pm 0.2$ vs post $1.0 \pm 0.7 \mathrm{pmol} / 1, p=0.02$ ),
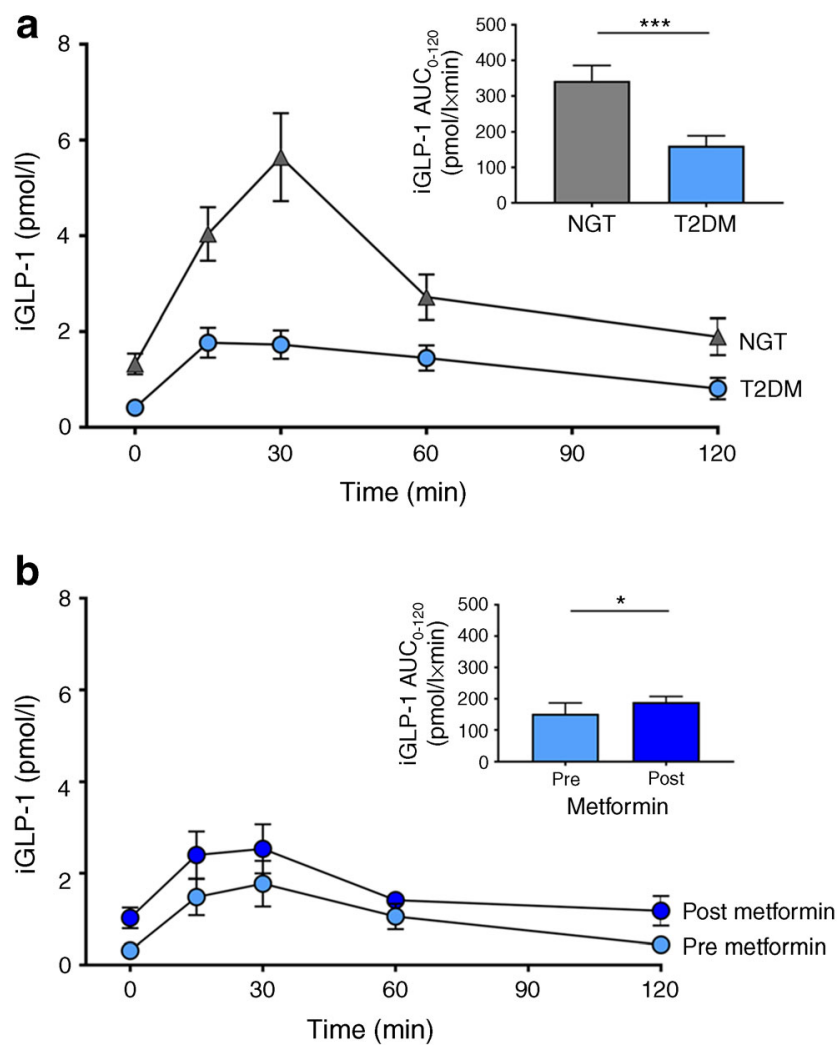

Fig. 1 iGLP-1 concentrations during a $2 \mathrm{~h}$ OGTT in youth with NGT (grey triangles, $n=10$ ) and type 2 diabetes (light blue circles, $n=18$ ) at visit 2 (a) and in youth with type 2 diabetes pre metformin at visit 2 (light blue circles, $n=8$ ) and post metformin at visit 5 (dark blue circles, $n=8$ ) (b). Inset bar graphs show iGLP AUC for the $2 \mathrm{~h}$ test $\left(\mathrm{AUC}_{0-120}\right)$. Data are mean \pm SEM. Variables are compared with Student's $t$ test (NGT vs type 2 diabetes) and paired $t$ test (pre vs post metformin). $* p<0.05$ and $* * * p<0.001$. T2DM, type 2 diabetes
$2 \mathrm{~h}$ (pre $0.4 \pm 0.2$ vs post $1.2 \pm 0.9 \mathrm{pmol} / \mathrm{l}, p=0.06$ ) and AUC $_{120}$ iGLP-1 increased by $\sim 50 \%$ (Fig. 1b); fasting (pre $6.3 \pm 2.2$ vs post $10.5 \pm 4.3 \mathrm{pmol} / \mathrm{l}, p<0.01)$ and $2 \mathrm{~h}$ PYY (pre $6.6 \pm 2.9$ vs post $9.0 \pm 4.0 \mathrm{pmol} / 1, p<0.01$ ) increased by $20-30 \%$ and there was no change in GIP (Fig. 2). Incretin concentrations in the type 2 diabetes group post metformin were similar to those in the NGT group (fasting iGLP-1 $1.0 \pm$ 0.6 vs $1.3 \pm 0.7 \mathrm{pmol} / 1, p=0.35$; PYY $10.5 \pm 4.3$ vs $9.7 \pm$ $5.2 \mathrm{pmol} / 1, p=0.72$ ). The fold change in fasting and $2 \mathrm{~h}$ iGLP-1 was $6.2 \pm 7.9$ and $2.2 \pm 2.6$, respectively. There was a non-significant negative correlation between the fold change in fasting iGLP-1 and $2 \mathrm{~h}$ glucose post metformin $(r=-0.64, p=$ 0.08 ) but no association between fold change in GLP-1 and IGI $(r=0.1, p=0.87)$.

Fasting steady-state kinetic measurements Steady-state glucose, insulin and $\beta$-hydroxybutyrate concentrations were higher in youth with type 2 diabetes compared with NGT (Table 2). Post metformin, insulin was non-significantly lower but otherwise there were no differences in glucose, lactate, glycerol, glucagon, ketones or $\beta$-hydroxybutyrate (Table 2). Rates of glucose production were similar in youth with type 2 diabetes and those with NGT, and were not changed by metformin therapy (Fig. 3a). Youth with type 2 diabetes had $\sim 20 \%$ higher rates of glycerol turnover, $\sim 10 \%$ higher fractional and absolute gluconeogenesis $\left(10.0 \pm 1.7\right.$ vs $7.2 \pm 1.1 \mu \mathrm{mol} \mathrm{\textrm {kg } _ { \mathrm { FFM } }}{ }^{-1} \mathrm{~min}^{-1}$, $p<0.001)$, and higher whole-body lipolysis $(5.2 \pm 0.9$ vs $4.0 \pm$ $\left.1.4 \mu \mathrm{mol} \mathrm{kg} \mathrm{FFM}^{-1} \mathrm{~min}^{-1}, p<0.01\right)$ compared with those with NGT. But these rates did not change with metformin therapy: rates of glucose production $(15.0 \pm 3.9$ vs $14.9 \pm 2.2 \mu \mathrm{mol}$ $\left.\mathrm{kg}_{\mathrm{FFM}}{ }^{-1} \min ^{-1}, p=0.84\right)$, absolute gluconeogenesis $(9.9 \pm 1.8$ vs $\left.9.7 \pm 1.7 \mu \mathrm{mol} \mathrm{kg} \mathrm{FFM}^{-1} \min ^{-1}, p=0.76\right)$ or whole-body lipol-

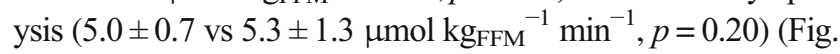
$3 \mathrm{~b}-\mathrm{d})$. HISI $_{\mathrm{GPR}}$ was $\sim 56 \%$ lower in youth with type 2 diabetes compared with NGT (median [25th-75th percentile] 9.6 [7.512.7] vs 21.3 [16.5-41.8], $p=0.01$ ) and did not change pre vs post metformin (median [25th-75th percentile] 8.7 [7.3-10.4] vs 11.4 [10-16.3], $p=0.10)$.

Metformin plasma concentrations At visit 2, metformin concentrations were undetectable or at the lower limit of detection (ESM Table 1). After 3 months, metformin concentrations varied but uniformly increased (range 0.20 $9.49 \mu \mathrm{mol} / 1$; ESM Table 1). The change in metformin concentrations did not correlate with changes in absolute gluconeogenesis $(r=-0.43, p=0.25)$, fractional gluconeogenesis $(r=$ $0.58, p=0.23)$, glucose production $(r=0.35, p=0.40)$, $\operatorname{HISI}_{\mathrm{GPR}}(r=0.09, p=0.82)$, IGI $(r=-0.70, p=0.06)$, fasting iGLP-1 $(r=0.03, p=0.93)$ or $2 \mathrm{~h}$ iGLP-1 $(r=0.27, p=0.52)$. In post hoc sensitivity analyses, there were no differences in post metformin iGLP-1 or rates of gluconeogenesis in youth who were treatment naive vs those on metformin prior to the study (ESM Table 1). 

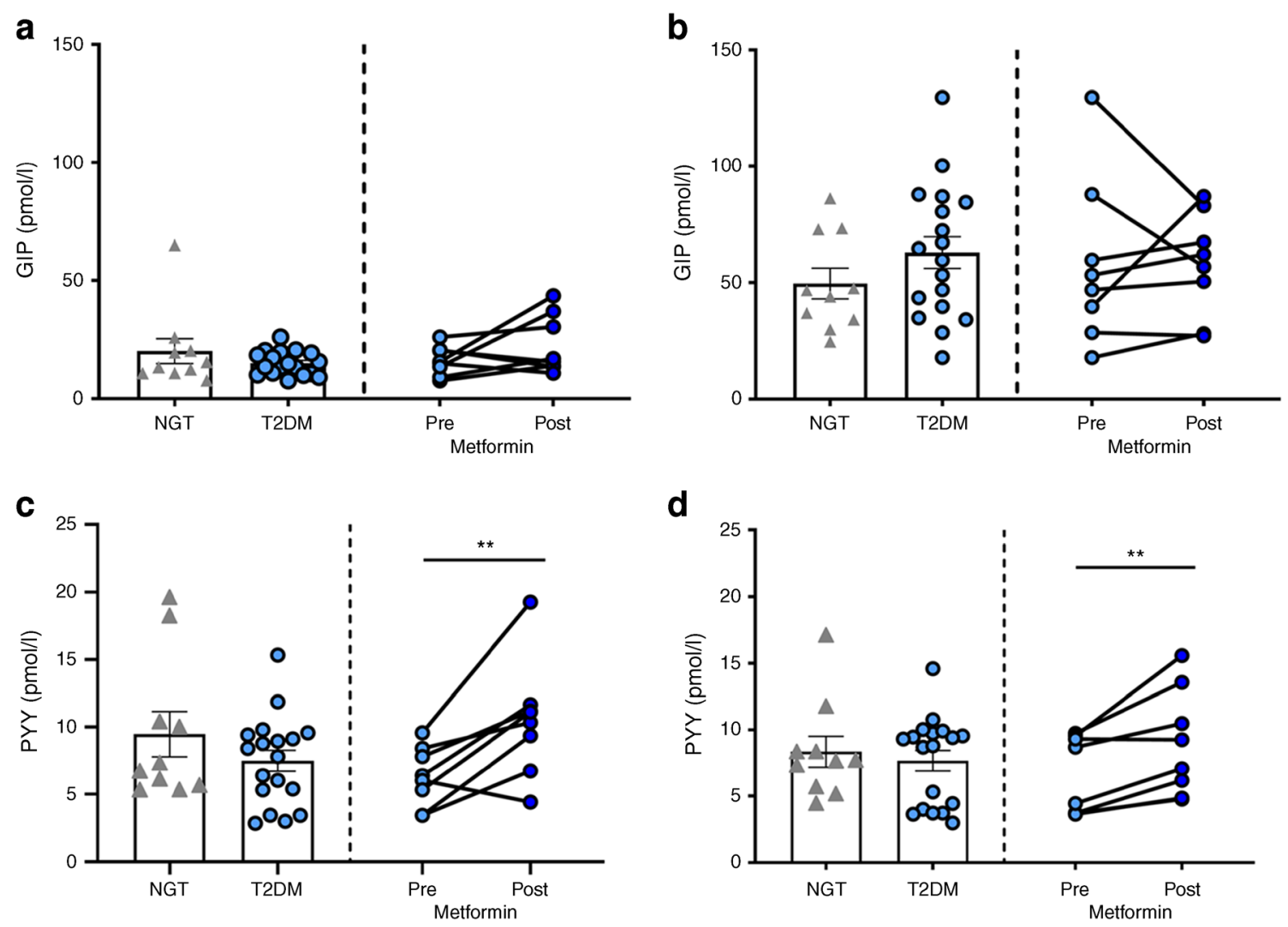

d

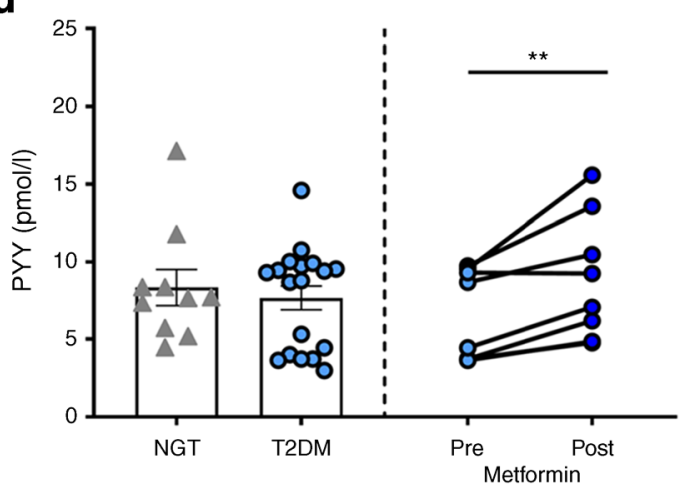

Fig. 2 Fasting and $2 \mathrm{~h}$ incretin hormone concentrations in youth with NGT and type 2 diabetes. Fasting total GIP concentrations (a), 2 h GIP (b), fasting PYY (c) and $2 \mathrm{~h}$ PYY (d) in youth with NGT (grey triangles, $n=10$ ) and type 2 diabetes (light blue circles, $n=18$ ) at visit 2, and in youth with type 2 diabetes pre metformin at visit 2 (light blue circles, $n=$

\section{Discussion}

This study systematically evaluated two important mechanisms of metformin action to provide insight into the clinical challenge of high treatment failure rates in youth with type 2 diabetes. Short-term metformin treatment improved

8 ) and post metformin (dark blue circles, $n=8$ ) at visit 5. Data are mean \pm SEM in bar graphs or individual values in line graphs. Variables are compared with Student's $t$ test (NGT vs type 2 diabetes) and paired $t$ test (pre vs post metformin). $* * p<0.01$. T2DM, type 2 diabetes

postprandial hyperglycaemia but was not associated with basal changes in gluconeogenesis, hepatic insulin sensitivity or glycerol turnover in youth with type 2 diabetes who were within 3 years of diagnosis and who had moderate fasting hyperglycaemia. Rather, short-term metformin treatment was associated with modest but significant increases in iGLP-1

Table 2 Steady-state concentrations in youth with obesity and type 2 diabetes

\begin{tabular}{|c|c|c|c|c|c|c|}
\hline \multirow[t]{2}{*}{ Variable } & \multirow[t]{2}{*}{$\operatorname{NGT}(n=10)$} & \multirow{2}{*}{$\begin{array}{l}\text { Type } 2 \text { diabetes } \\
(n=18)\end{array}$} & \multirow{2}{*}{$\begin{array}{l}p \text { value NGT vs type } 2 \\
\text { diabetes }\end{array}$} & \multicolumn{3}{|c|}{ Type 2 diabetes $(n=9)$} \\
\hline & & & & Pre metformin & Post metformin & $\begin{array}{l}p \text { value pre vs } \\
\text { post }\end{array}$ \\
\hline Glucose, $\mathrm{mmol} / \mathrm{l}$ & $4.4 \pm 0.4$ & $6.5 \pm 2.2$ & 0.03 & $6.3 \pm 0.5$ & $5.8 \pm 0.3$ & 0.26 \\
\hline Insulin, pmol/1 & $\begin{array}{l}133.3 \\
\quad(88.2-177.1)\end{array}$ & $268.1(222.9-331.3)$ & 0.003 & $\begin{array}{l}302.8 \\
\quad(228.5-331.3)\end{array}$ & $\begin{array}{l}191.7 \\
\quad(149.3-284.1)\end{array}$ & 0.07 \\
\hline Lactate, $\mathrm{mmol} / \mathrm{l}$ & $0.88 \pm 0.20$ & $1.13 \pm 0.34$ & 0.06 & $1.13 \pm 0.44$ & $1.08 \pm 0.29$ & 0.70 \\
\hline Glycerol, mmol/1 & $0.11 \pm 0.04$ & $0.13 \pm 0.05$ & 0.18 & $0.14 \pm 0.04$ & $0.15 \pm 0.06$ & 0.69 \\
\hline Glucagon, pmol/1 & $25.4 \pm 15.1$ & $14.9 \pm 5.6$ & 0.01 & $14.0 \pm 4.8$ & $15.2 \pm 7.6$ & 0.50 \\
\hline Total ketones, $\mu \mathrm{mol} / 1$ & $134.1 \pm 60.5$ & $323.8 \pm 303.2$ & 0.06 & $233.2 \pm 97.0$ & $189 \pm 54.5$ & 0.33 \\
\hline $\begin{array}{l}\beta \text {-Hydroxybutyrate, } \\
\mu \mathrm{mol} / 1\end{array}$ & $90.1 \pm 33.3$ & $209.8 \pm 169.2$ & 0.04 & $161.6 \pm 62.3$ & $140.0 \pm 29.8$ & 0.39 \\
\hline
\end{tabular}

Data are presented as mean \pm SD or median (25th-75th percentile) 

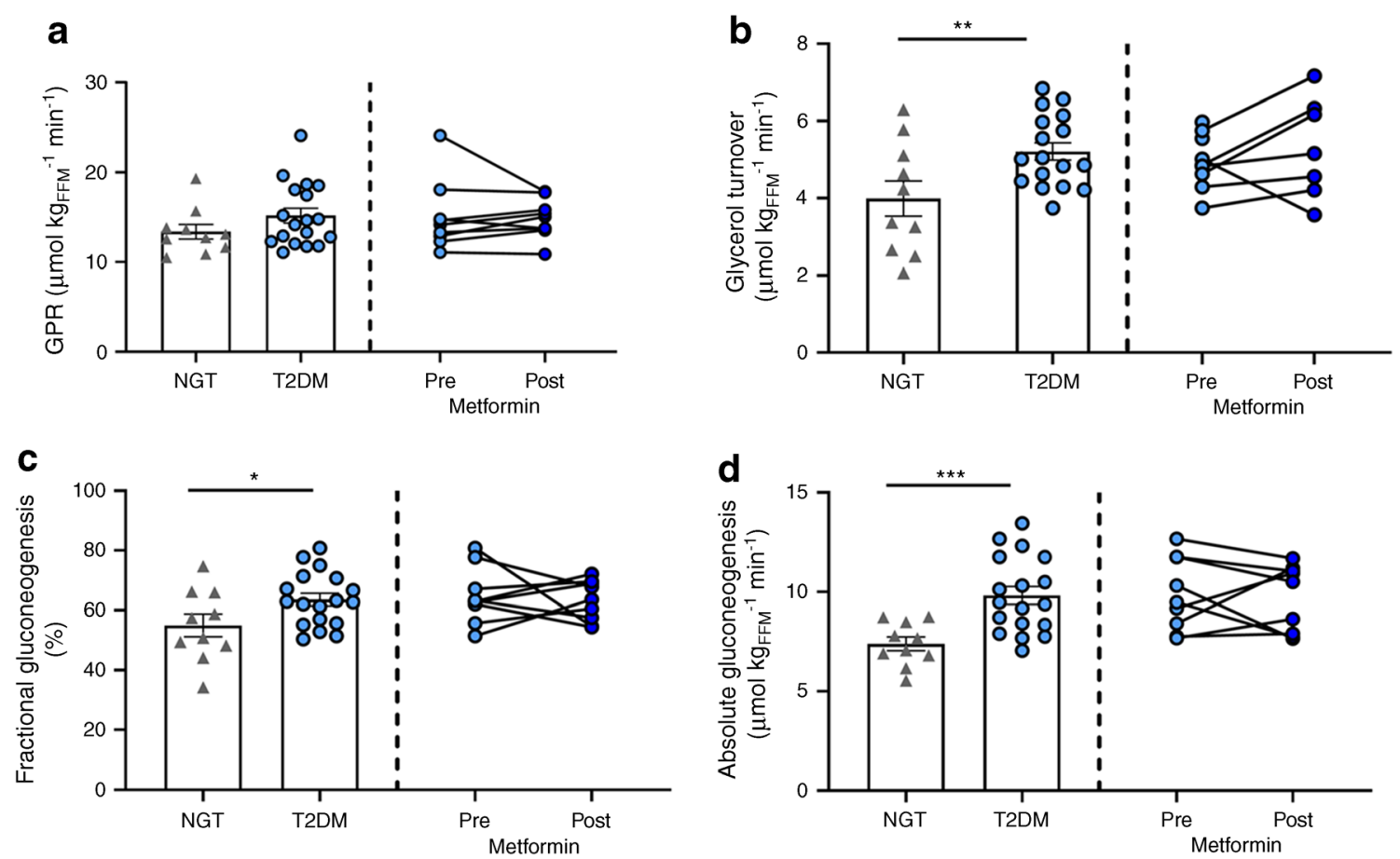

Fig. 3 Basal rates of glucose and glycerol turnover in youth with NGT and type 2 diabetes. GPR (a), glycerol turnover (b), fractional gluconeogenesis (c) and absolute gluconeogenesis (d) in youth with NGT (grey triangles, $n=10$ ) and type 2 diabetes (light blue circles, $n=18$ ) at visit 2 , and in youth with type 2 diabetes pre metformin at visit 2 (light blue

and total PYY concentrations. These findings were observed in the absence of shifts in BMI, insulin sensitivity, gluconeogenic substrates, metabolites or rates of gluconeogenesis. Specifically, these findings posit that short-term metformin may reduce blood glucose levels via increases in incretins in the absence of changes in gluconeogenesis.

These study results are impactful because we demonstrate a key link between metformin, enteric hormones and blood glucose levels in youth with type 2 diabetes. Both iGLP-1 and total PYY post metformin were restored to levels observed in youth with NGT, observations that add credence to the accumulating clinical evidence in adults that gut-based mechanisms may be a primary driver of metformin's glucoselowering effects [14, 16, 26, 27]. Data supporting metformin's direct or indirect enteric action are at the forefront of current investigations $[15,16]$. Metformin may directly inhibit dipeptidyl peptidase IV and GLP-1 catabolism [28], or indirectly stimulate enteroendocrine GLP-1 secretion via increasing the populations of short chain fatty acid-producing bacteria $[9,29,30]$. While this study did not explore the mechanisms underlying the increase in iGLP-1 and total PYY, our findings agree with the recent US Food and Drug Administration approval of liraglutide in youth, as combination therapy with metformin to improve overall blood glucose levels and incretin activity [31].

The observed increase in incretins in the absence of metformin-associated changes in gluconeogenesis and hepatic

circles, $n=9$ ) and post metformin at visit 5 (dark blue circles, $n=9$ ). Data are mean \pm SEM in bar graphs or individual values in line graphs. Variables are compared with Student's $t$ test (NGT vs type 2 diabetes) and paired $t$ test (pre vs post metformin). $* p<0.05, * * p<0.01$ and $* * * p<0.001$. T2DM, type 2 diabetes

insulin sensitivity in youth is also important and novel for two main reasons. First, this paired analysis included detailed metabolic phenotyping of glucose and glycerol kinetics in youth with type 2 diabetes, using a reference group of peers, and with rigorous assessment of metformin concentrations to help elucidate heterogeneity in treatment response. Second, to our knowledge, there are no published studies of metformin mechanism of action in youth and no data that have concurrently evaluated its hepato-entero mechanisms in youth or adults. Of note, $70 \%(9 / 13)$ of the total sample recruited completed the treatment study and post hoc analyses supported the null hypothesis as only eight youth were needed to detect a $10 \%$ change in glucose production or fractional gluconeogenesis. Our study was therefore powered to detect an even larger effect size (30\% change in glucose production) observed in previous adult analyses [8,10-13].

Notably, our study findings are contrary to the popular consensus that metformin's primary mechanistic effect is to suppress gluconeogenesis. Yet, the pathways responsible for metformin's glucose-lowering properties have been highly debated over the last two decades. Overall, studies supporting metformin-induced inhibition of gluconeogenesis postulate that energy-dependent mechanisms are central to its ability to lower glucose production [32]. However, metformin-induced inhibition of mitochondrial complex 1 occurs at supraphysiological doses (20-200 mmol/l) whereas clinically relevant doses $(<100 \mu \mathrm{mol} /$ 1) have no effect on the activity of complex 1 in isolated 
mitochondria [9]. To corroborate our observations, we showed no change in gluconeogenic substrates (glycerol, lactate) post metformin, arguing against partitioning of substrates towards glycolysis or alterations in the cellular redox state [33]. We measured concentrations of $\beta$-hydroxybutyrate, a biomarker of hepatic fatty acid oxidation, and RQ to assess overall substrate oxidation and found no differences post metformin, suggesting no effect on lipogenesis. Finally, we assessed WBISI and wholebody lipolysis and found no differences post metformin, consistent with no significant effect of short-term metformin on wholebody or adipose tissue insulin sensitivity.

Our study results fill an important gap in the literature as there is a paucity of data evaluating the in vivo kinetic changes associated with metformin therapy in youth. Only five studies systematically examined the components of hepatic glucose production: two demonstrated reduction of gluconeogenesis in adults with severe hyperglycaemia $\left(\mathrm{HbA}_{1 \mathrm{c}}>85 \mathrm{mmol} / \mathrm{mol}\right.$ [10\%]) and three showed that metformin caused little or no reduction in glycogenolysis and no change in the rate of gluconeogenesis (ESM Table 2). The discrepancies observed among these adult trials may be related to differences in blood glucose levels among study participants or varying methodologies [34]. Specifically, in the two studies that reported a reduction in gluconeogenesis, total rates of gluconeogenesis were underestimated because the tracers only gave estimates of the fraction of glucose derived from the infused labelled tracer (i.e. carbon-labelled lactate or glycerol) $[10,12]$. In addition, because the studies' participants had severe hyperglycaemia, metformin's glucose-lowering effect may have also been related to changes in peripheral insulin sensitivity, but this was not measured in those studies. In the current study, we used the average deuterium method to evaluate the incorporation of deuterium into newly formed glucose to estimate the total contribution of all three-carbon substrates to gluconeogenesis. Our observations align with others arising from the deuterium incorporation method (with different analytical processing) that found no changes in basal or clamp-derived gluconeogenesis in adults with comparable $\mathrm{HbA}_{1 \mathrm{c}}$ [11]. Further, our findings agree with another randomised controlled trial of metformin in adults, demonstrating no change in rates of gluconeogenesis with shortterm therapy [8]. Together, these observations demonstrate marked variability in the ability of short-term metformin to lower rates of gluconeogenesis under basal or clamp conditions in youth and adults with modest hyperglycaemia. Notably, in our group of youth with type 2 diabetes we observed heterogeneity in metformin concentrations as well as in the change in rates of fractional gluconeogenesis and HISI $_{\text {GPR }}$. In contrast to the uniform increase in iGLP-1 and PYY, only $4 / 9$ youth had $>6 \%$ suppression in fractional gluconeogenesis suggesting that certain phenotypic traits may predict metformin's hepatic effect. Therefore, we conducted sensitivity analyses to determine whether baseline $\mathrm{HbA}_{1 \mathrm{c}}$ or prior metformin treatment were mediating factors. Neither the levels of blood glucose nor prior metformin treatment were associated with the changes in incretin hormones or rates of gluconeogenesis. In addition, the change in metformin concentrations did not correlate with the changes in incretin hormone concentrations or rates of fractional gluconeogenesis. Therefore, the factors mediating metformin's effect on glucose production remain to be elucidated.

The wide distribution of metformin concentrations achieved after treatment could be a potential mediator. Previous studies have indicated an inconsistent relationship between metformin's pharmacokinetic and pharmacodynamic responses [19] and metformin plasma concentrations vary widely at therapeutic doses with up to a 40 -fold variation [35]. Although not assessed in this small study, genetic polymorphisms of metformin uptake or excretion may explain the large interindividual variations in metformin concentrations but they have not been reliably linked to metformin's glucose-lowering effects [36-38]. Additional research among larger sample sizes in youth and adults is needed to determine the clinical importance of these genetic polymorphisms and how they might predict clinical metformin response [39].

Some study limitations warrant mention. This study examined a relatively small, predominantly female, group of youth in the basal state pre and post metformin. As clamp-derived measures of hepatic or peripheral insulin sensitivity were lacking, we had limited power to detect small changes in insulin sensitivity. Nevertheless, the paired study design was adequately powered to determine clinically relevant changes in GPR and gluconeogenesis and the sample size was comparable with those of other stable isotope studies examining metformin's in vivo glucoselowering effects [8, 10-13]. Additionally, although we only recruited youth with mild to moderate hyperglycaemia $\left(\mathrm{HbA}_{1 \mathrm{c}}\right.$ $<75 \mathrm{mmol} / \mathrm{mol}$ [9\%]), there may have been heterogeneity in disease severity as youth with type 2 diabetes ranged from newly diagnosed to 3 years post diagnosis. Further, our findings may not be generalisable to youth with severe hyperglycaemia or those on chronic treatment and, due to limitations in sample size, we were only able to explore potential mediators of metformin response. Lastly, the high proportion of female participants evaluated in this study is reflective of the natural history of type 2 diabetes in youth [40] and our study results may not be generalisable to males, although there is no evidence to suggest that there are sex differences in glucose production or response to metformin therapy [41].

\section{Conclusion}

This novel study in youth with type 2 diabetes demonstrated that short-term metformin improved postprandial blood glucose levels and was associated with modest increases in incretin concentrations in the absence of changes in rates of glucose production and gluconeogenesis. These findings shed 
new light on metformin's mechanism of action in youth with type 2 diabetes, who have a high risk for metabolic complications and limited therapeutic options. Our findings support the need to explore targeted combination therapy to reduce the increased rates of gluconeogenesis and to augment incretin response in youth with type 2 diabetes early in their disease course. Larger long-term studies in youth are warranted to further elucidate the role of incretins and metformin concentrations in predicting metformin's glucose-lowering effects.

Acknowledgements We would like to thank the volunteers (and their families) whose participation made this study possible. We gratefully acknowledge and thank the following individuals at NIDDK/DEOB, NIH, USA: K. Chen and R. Brychta for assisting with accelerometer data processing; and A. Villalobos-Perez and S. Matta for editing the manuscript. Some of the data were presented as a poster abstract at the 79th Scientific Sessions of the ADA, San Francisco, 7-10 June 2019 and as an oral abstract at the Obesity Week, Las Vegas, 3-7 November 2019.

Data availability The datasets generated and/or analysed during the current study are available from the corresponding author on reasonable request.

Funding The Division of Intramural Research supports STC, LM, HC, YD, MW, PW (National Institute of Diabetes \& Digestive \& Kidney Diseases), AC and SY (the NIH Clinical Center), and AM (National Institute of Child Health and Development). The project was supported by NIH grants RO1DK 55478 (MWH) and USDA/ARS 6250-5100 (MWH), and the Marilyn Fishman Endocrine Fellows Foundation grant (STC).

Authors' relationships and activities The authors declare that there are no relationships or activities that might bias, or be perceived to bias, their work.

Contribution statement STC conceptualised and designed the study, recruited and collected the data, conducted the analysis and wrote the manuscript. MWH conceptualised and designed the study, and revised and edited the manuscript. CC, AC, SS, YD, SC, SY, HC, PW, MW, LM, $\mathrm{AM}$ and SNM made substantial contributions to study design, data collection and analysis, and revising and editing the manuscript. FC made substantial contributions to study recruitment, data acquisition and analysis, and revising for intellectual content. STC is the guarantor of this work and, as such, had full access to all data in the study and takes responsibility for the integrity of the data and the accuracy of the data analysis. All authors gave final approval of the version to be published.

\section{References}

1. Zeitler P, Hirst K, Pyle L et al (2012) A clinical trial to maintain glycemic control in youth with type 2 diabetes. N Engl J Med 366(24):2247-2256. https://doi.org/10.1056/NEJMoa1109333

2. Yki-Jarvinen H (2007) ADOPT: lessons from comparison of glycemic durability of rosiglitazone, metformin, or glyburide monotherapy. Curr Diab Rep 7(3):173-174. https://doi.org/10.1007/s11892007-0028-0

3. Kahn SE, Lachin JM, Zinman B et al (2011) Effects of rosiglitazone, glyburide, and metformin on beta-cell function and insulin sensitivity in ADOPT. Diabetes 60(5):1552-1560. https:// doi.org/10.2337/db10-1392

4. Kelsey MM, Geffner ME, Guandalini C et al (2016) Presentation and effectiveness of early treatment of type 2 diabetes in youth: lessons from the TODAY study. Pediatr Diabetes 17(3):212-221. https://doi.org/10.1111/pedi.12264

5. Walders-Abramson N, Venditti EM, Ievers-Landis CE et al (2014) Relationships among stressful life events and physiological markers, treatment adherence, and psychosocial functioning among youth with type 2 diabetes. J Pediatr 165(3):504-508.e501. https:// doi.org/10.1016/j.jpeds.2014.05.020

6. Chung S, Hsia D, Chacko S, Rodriguez L, Haymond M (2015) Increased gluconeogenesis in youth with newly diagnosed type 2 diabetes. Diabetologia 58(3):596-603. https://doi.org/10.1007/ s00125-014-3455-x

7. Sekizkardes H, Chung ST, Chacko S et al (2020) Free fatty acid processing diverges in human pathologic insulin resistance conditions. J Clin Invest. https://doi.org/10.1172/jci135431

8. Cusi K, Consoli A, DeFronzo RA (1996) Metabolic effects of metformin on glucose and lactate metabolism in noninsulindependent diabetes mellitus. J Clin Endocrinol Metab 81(11): 4059-4067. https://doi.org/10.1210/jcem.81.11.8923861

9. Foretz M, Guigas B, Viollet B (2019) Understanding the glucoregulatory mechanisms of metformin in type 2 diabetes mellitus. Nat Rev Endocrinol 15(10):569-589. https://doi.org/10. 1038/s41574-019-0242-2

10. Hundal RS, Krssak M, Dufour S et al (2000) Mechanism by which metformin reduces glucose production in type 2 diabetes. Diabetes 49(12):2063-2069. https://doi.org/10.2337/diabetes.49.12.2063

11. Basu R, Shah P, Basu A et al (2008) Comparison of the effects of pioglitazone and metformin on hepatic and extra-hepatic insulin action in people with type 2 diabetes. Diabetes 57(1):24-31. https://doi.org/10.2337/db07-0827

12. Stumvoll M, Nurjhan N, Perriello G, Dailey G, Gerich JE (1995) Metabolic effects of metformin in non-insulin-dependent diabetes mellitus. N Engl J Med 333(9):550-554. https://doi.org/10.1056/ NEJM199508313330903

13. Christiansen MP, Hellerstein MK (1998) Effects of metformin on hepatic glucose metabolism. Curr Opin Endocrinol Diabetes Obes 5(4):252-255

14. Sun EW, Martin AM, Wattchow DA et al (2019) Metformin triggers PYY secretion in human gut mucosa. J Clin Endocrinol Metab 104(7):2668-2674. https://doi.org/10.1210/jc.2018-02460

15. Napolitano A, Miller S, Nicholls AW et al (2014) Novel gut-based pharmacology of metformin in patients with type 2 diabetes mellitus. PLoS One 9(7):e100778. https://doi.org/10.1371/journal. pone. 0100778

16. Bahne E, Sun EWL, Young RL et al (2018) Metformin-induced glucagon-like peptide-1 secretion contributes to the actions of metformin in type 2 diabetes. JCI Insight 3(23):e93936. https:// doi.org/10.1172/jci.insight.93936

17. Mannucci E, Tesi F, Bardini G et al (2004) Effects of metformin on glucagon-like peptide-1 levels in obese patients with and without type 2 diabetes. Diabetes Nutr Metab 17(6):336-342

18. American Diabetes Association (2019) Standards of care in diabetes. Diabetes Care 42(Suppl 1):1-204

19. Graham GG, Punt J, Arora M et al (2011) Clinical pharmacokinetics of metformin. Clin Pharmacokinet 50(2):81-98. https://doi.org/ 10.2165/11534750-000000000-00000

20. Mifflin MD, St Jeor ST, Hill LA, Scott BJ, Daugherty SA, Koh YO (1990) A new predictive equation for resting energy expenditure in healthy individuals. Am J Clin Nutr 51(2):241-247. https://doi.org/ 10.1093/ajcn/51.2.241

21. Chacko S, Sunehag A, Sharma S, Sauer PJJ, Haymond M (2008) Measurement of gluconeogenesis using glucose fragments and mass spectrometry after ingestion of deuterium oxide. J Appl 
Physiol 104(4):944-951. https://doi.org/10.1152/japplphysiol. 00752.2007

22. Sunehag AL, Treuth MS, Toffolo G et al (2001) Glucose production, gluconeogenesis, and insulin sensitivity in children and adolescents: an evaluation of their reproducibility. Pediatr Res 50(1):115-123. https://doi.org/10.1203/00006450-20010700000021

23. Chung ST, Courville AB, Onuzuruike AU et al (2018) Gluconeogenesis and risk for fasting hyperglycemia in black and white women. JCI Insight 3(18):e121495. https://doi.org/10.1172/ jci.insight. 121495

24. Matsuda M, DeFronzo RA (1999) Insulin sensitivity indices obtained from oral glucose tolerance testing: comparison with the euglycemic insulin clamp. Diabetes Care 22(9):1462-1470. https://doi.org/10.2337/diacare.22.9.1462

25. Ferrannini E, Gastaldelli A, Miyazaki Y, Matsuda M, Mari A, DeFronzo RA (2005) $\beta$-Cell function in subjects spanning the range from normal glucose tolerance to overt diabetes: a new analysis. J Clin Endocrinol Metab 90(1):493-500. https://doi.org/10. 1210/jc.2004-1133

26. Borg MJ, Bound M, Grivell J et al (2019) Comparative effects of proximal and distal small intestinal administration of metformin on plasma glucose and glucagon-like peptide-1, and gastric emptying after oral glucose, in type 2 diabetes. Diabetes Obes Metab 21(3): 640-647. https://doi.org/10.1111/dom.13567

27. Preiss D, Dawed A, Welsh P et al (2017) Sustained influence of metformin therapy on circulating glucagon-like peptide-1 levels in individuals with and without type 2 diabetes. Diabetes Obes Metab 19(3):356-363. https://doi.org/10.1111/dom.12826

28. Thondam SK, Cross A, Cuthbertson DJ, Wilding JP, Daousi C (2012) Effects of chronic treatment with metformin on dipeptidyl peptidase- 4 activity, glucagon-like peptide 1 and ghrelin in obese patients with type 2 diabetes mellitus. Diabet Med 29(8):e205e210. https://doi.org/10.1111/j.1464-5491.2012.03675.x

29. Wu H, Esteve E, Tremaroli V et al (2017) Metformin alters the gut microbiome of individuals with treatment-naive type 2 diabetes, contributing to the therapeutic effects of the drug. Nat Med 23(7): 850-858. https://doi.org/10.1038/nm.4345

30. de la Cuesta-Zuluaga J, Mueller NT, Corrales-Agudelo V et al (2017) Metformin is associated with higher relative abundance of mucin-degrading Akkermansia muciniphila and several short-chain fatty acid-producing microbiota in the gut. Diabetes Care 40(1):54 62. https://doi.org/10.2337/dc16-1324

31. Tamborlane WV, Barrientos-Perez M, Fainberg U et al (2019) Liraglutide in children and adolescents with type 2 diabetes. $\mathrm{N}$
Engl J Med 381(7):637-646. https://doi.org/10.1056/ NEJMoa1903822

32. Bridges HR, Jones AJ, Pollak MN, Hirst J (2014) Effects of metformin and other biguanides on oxidative phosphorylation in mitochondria. Biochem J 462(3):475-487. https://doi.org/10.1042/ BJ20140620

33. Madiraju AK, Erion DM, Rahimi Y et al (2014) Metformin suppresses gluconeogenesis by inhibiting mitochondrial glycerophosphate dehydrogenase. Nature 510(7506):542-546. https://doi. org/10.1038/nature13270

34. Chung ST, Chacko SK, Sunehag AL, Haymond MW (2015) Measurements of gluconeogenesis and glycogenolysis: a methodological review. Diabetes 64(12):3996-4010. https://doi.org/10. 2337/db15-0640

35. Kajbaf F, De Broe ME, Lalau JD (2016) Therapeutic concentrations of metformin: a systematic review. Clin Pharmacokinet 55(4): 439-459. https://doi.org/10.1007/s40262-015-0323-x

36. Choi JH, Yee SW, Ramirez AH et al (2011) A common $5^{\prime}$-UTR variant in MATE2-K is associated with poor response to metformin. Clin Pharmacol Ther 90(5):674-684. https://doi.org/10.1038/clpt. 2011.165

37. Stocker SL, Morrissey KM, Yee SW et al (2013) The effect of novel promoter variants in MATE1 and MATE2 on the pharmacokinetics and pharmacodynamics of metformin. Clin Pharmacol Ther 93(2):186-194. https://doi.org/10.1038/clpt.2012.210

38. Becker ML, Visser LE, van Schaik RH, Hofman A, Uitterlinden AG, Stricker BH (2009) Genetic variation in the organic cation transporter 1 is associated with metformin response in patients with diabetes mellitus. Pharmacogenomics J 9(4):242-247. https://doi. org/10.1038/tpj.2009.15

39. Florez JC (2017) The pharmacogenetics of metformin. Diabetologia 60(9):1648-1655. https://doi.org/10.1007/s00125017-4335-y

40. Jensen ET, Dabelea D (2018) Type 2 diabetes in youth: new lessons from the SEARCH study. Curr Diab Rep 18(6):36. https://doi.org/ 10.1007/s11892-018-0997-1

41. Basu A, Dube S, Basu R (2017) Men ARE from Mars, women are from Venus: sex differences in insulin action and secretion. Adv Exp Med Biol 1043:53-64. https://doi.org/10.1007/978-3-31970178-3 4

Publisher's note Springer Nature remains neutral with regard to jurisdictional claims in published maps and institutional affiliations. 